\title{
Rumenotomia em bovinos: uso da paramentação e de oxitetraciclina parenteral na profilaxia de complicações pós-operatórias
}

\author{
Bovine rumenotomy: use of garment and parenteral oxytetraciclyne \\ prophylaxis on post-operative complications
}

\author{
Luiz Antônio Franco da Silva ${ }^{1}$ Duvaldo Eurides ${ }^{2}$ Gabrielly Fernandes Salazar da Silva ${ }^{3}$ \\ Jefferson Henrique Silva Monteiro ${ }^{3}$ Eline Silveira de Matos $^{3}$ Glauciane Ribeiro de Castro ${ }^{4}$ \\ Ediane Batista da Silva ${ }^{4}$ Olízio Claudino da Silva ${ }^{5}$ Maria Clorinda Soares Fioravanti ${ }^{6}$
}

RESUMO

Utilizou-se a paramentação e a oxitetraciclina parenteral na profilaxia de complicações pós-operatórias em 28 bovinos fêmeas submetidos à rumenotomia, distribuídos em quatro grupos de sete animais. Nos bovinos dos grupos I (GI) e II (GII), as rumenotomias foram realizadas seguindo normas de paramentação do cirurgião e do auxiliar, enquanto que, nos animais dos grupos III (GIII) e IV (GIV), essa conduta não foi adotada. No pós-operatório, utilizou-se antibiotico parenteral à base de oxitetraciclina nos animais do GI e GIII. As principais complicações observadas no pósoperatório foram: edema, enfisema subcutâneo, deiscência de pontos da ferida de sutura e peritonite. Verificou-se que a paramentação contribuiu positivamente na redução do tempo de cicatrização. O uso parenteral de antibiótico não influenciou no tempo de recuperação dos animais, quando o cirurgião e o auxiliar não se paramentaram.

Palavras-chave: rumenotomia, antibiotico, paramentação, bovino.

\section{ABSTRACT}

The effects of surgical garment of surgeon and auxiliary and the use of antibiotic were evaluated for the occurrence of postoperative complications in 28 cows submitted to rumenotomy. The cours were equally allotted to the following groups: Group I (GI) and II (GII), rumenotomy performed following standard surgery garment procedures for both surgeon and auxiliary; groups III (GIII) and IV (GIV) rumenotomy performed without garment. On the postoperative, parenteral antibiotic with oxytetracycline was used on groups I and III. The main complications observed were: edema, subcutaneous emphysema, wound dehiscence and peritonitis. Surgical garmenting contributed positively to reduce healing time. The antibiotic used did not influence recovery time within groups without surgical garmenting of surgeon and auxiliary.

Key words: rumenotomy, cattle, antibiotic, surgical garment.

\section{INTRODUÇÃO}

A rumenotomia em bovinos é utilizada como meio de diagnóstico e no tratamento de timpanismo, acidose rumenal, reticulite, reticuloperitonite traumática, sobrecarga, compactação, atonia do omaso ou do abomaso, e para

${ }^{1}$ Professor Adjunto do Departamento de Medicina Veterinária, Escola de Veterinária, Universidade Federal de Goiás (UFG), Goiânia, Go. Rua 18A, n.591, Ed. Acauã, apto. 502, St. Aeroporto, 74070-060, Goiânia, Go, Brasil. E-mail: lafranco@vet.ufg.br.

${ }^{2}$ Professor Titular do Departamento de Medicina Veterinária, Faculdade de Medicina Veterinária, Universidade Federal de Uberlândia, Uberlândia, MG, Brasil.

${ }^{3}$ Médicos Veterinários Autônomos, Goiânia, Go, Brasil.

${ }^{4}$ Mestrandos em Ciência Animal da Escola de Veterinária, UFG, Goiânia, Go, Brasil.

${ }^{5}$ Professor Assistente do Departamento de Medicina Veterinária da Escola de Veterinária, UFG, Goiânia-Goiás, Brasil..

${ }^{6}$ Professor Adjunto do Departamento de Medicina Veterinária da Escola de Veterinária, UFG, Goiânia-Goiás, Brasil. 
remover corpos estranhos como fios metálicos de fardo de feno e sacos plásticos localizados no segmento digestivo entre o retículo e omaso ou no esôfago distal, sobre a base do coração (DEHGHANI \& GHADRDANI, 1995; EL-MAGHRABY \& HAILAT, 2001). Na maioria das vezes, os procedimentos cirúrgicos são realizados em condições inadequadas e os cirurgiões ignoram o uso de roupas, luvas e instrumental esterilizados. Todavia, mesmo que o nível ideal de assepsia seja inatingível, na prática, recomenda-se trabalhar dentro de padrão asséptico mais elevado possível para não se colocar em risco o bem estar do paciente e a reputação do profissional. $\mathrm{O}$ cirurgião deverá preparar o campo operatório adequadamente, usar luvas, avental, gorro e máscara, embora tal vestuário apresente certas limitações nas abordagens cirúrgicas de grandes animais a campo. A decisão pela paramentação cabe somente ao profissional, mesmo sabendo que o uso de luvas serve para proteger o próprio cirurgião (TURNER \& McILWRAITH, 2002).

Segundo KNECHT et al. (1985), antecedendo os procedimentos cirúrgicos, existem discordâncias quanto à preparação do campo operatório, mas constitui um consenso a necessidade de se realizar a tricotomia, escovamento e aplicação tópica de germicida, sendo de eleição, o iodo e seus derivados. Os membros da equipe cirúrgica e assistentes são fontes potenciais de contaminação, portanto, a paramentação, os bons hábitos e os cuidados com a higiene pessoal devem ser lembrados na preparação do cirurgião. Para GONZALO et al. (1994), a higienização das mãos e antebraços do cirurgião é realizada com o objetivo de reduzir ao máximo o número de microrganismos, remover gordura da pele e manter um prolongado efeito depressor sobre a microflora.

Procedimentos cirúrgicos como rumenotomia e rumenostomia podem resultar em complicações pós-operatórias, inclusive levar o animal a óbito. Devido ao reduzido número de trabalhos científicos publicados, poucas informações foram obtidas, sobretudo quanto à paramentação do cirurgião e o uso de antibióticos nesses casos. BLESSING (1971) afirmou que algumas condições préoperatórias devem ser consideradas, como tamanho e o peso do animal, confiável método de anestesia geral e a manutenção da assepsia no decorrer da cirurgia. Deve-se utilizar material de sutura resistente e de composição adequada, sendo a síntese suficiente para apoiar e conter as vísceras abdominais. Finalmente, sugere-se que o conjunto de medidas pré, trans e pósoperatórias seja suficiente para reduzir algumas complicações pós-operatórias que ocasionalmente possam surgir.

O objetivo deste trabalho foi avaliar os efeitos da paramentação e da antibioticoterapia sobre a ocorrência de complicações pós-operatórias em bovinos submetidos à rumenotomia.

\section{MATERIAL E MÉTODOS}

O estudo foi realizado na Escola de Veterinária da Universidade Federal de Goiás (UFG), no período de agosto de 1994 a novembro de 2002. Foram utilizadas 28 fêmeas bovinas, saudáveis, da raça Girolando, peso médio de $250 \mathrm{~kg}$ e faixa etária de 20 meses. Durante o estudo, os animais foram mantidos em pasto de Brachiaria sp, com água à vontade oferecida em bebedouro tipo australiano.

Após serem submetidos ao exame clínico (ROSENBERGER, 1993), os bovinos foram alocados, aleatoriamente, em quatro grupos contendo sete animais. Nos bovinos do grupo I (GI), as rumenotomias foram realizadas seguindo normas de paramentação do cirurgião e do auxiliar recomendadas por TURNER \& McILWRAITH (2002) e, durante o pós-operatório, utilizou-se antibiótico parenteral. Para operar os animais que compuseram o grupo II (GII), adotou-se a devida paramentação dos cirurgiões, porém não se aplicou antibiótico no pós-operatório. Quanto aos animais do grupo III (GIII), os procedimentos cirúrgicos foram realizados sem a preocupação com a paramentação do cirurgião, mas adotou-se o uso de antibiótico parenteral no pós-operatório. Os bovinos do grupo IV (GIV) foram submetidos ao mesmo procedimento utilizado para o GIII, porém não se empregou antibiótico parenteral.

O pré-operatório, independente do grupo ao qual os animais pertenciam, constituiu-se de jejum alimentar e hídrico de 18 horas, tranqüilização com cloridrato de xilazina a $2 \%$ a na dose de $0,1 \mathrm{mg} \mathrm{kg}^{-1}$ de peso corporal, contenção em decúbito lateral direito, tricotomia na região do flanco esquerdo, higienização com solução de iodo ${ }^{\mathrm{b}}$ e anestesia local com cloridrato de lidocaína a $2 \%$ c empregando-se o método do " $L$ " invertido (MASSONE, 2003).

A preparação do cirurgião e do auxiliar, independente do procedimento adotado para todos os grupos, constou, primeiramente, de higienização seqüenciada das mãos e antebraços com água corrente e sabão, hipoclorito de sódio a 0,5\% e solução de iodo na concentração de 1:250 (SILVA et al., 2002). Para operar os bovinos dos grupos GI e GII, o cirurgião e o auxiliar utilizaram aventais cirúrgicos, luvas e instrumental cirúrgico previamente esterilizados. Nas 
cirurgias dos bovinos pertencentes aos grupos GIII e GIV, cirurgião e auxiliar não se paramentaram, mas usaram instrumental cirúrgico esterilizado. A técnica cirúrgica adotada em todos os grupos fundamentouse nas recomendações de LAZZERI (1994), e os procedimentos cirúrgicos não obedeceram a um protocolo definido, sendo os animais operados durante todo o tempo do experimento.

Independente do grupo ao qual os animais pertenciam, o procedimento cirúrgico foi realizado sempre pelo mesmo cirurgião e obedeceu à mesma seqüência, iniciando-se pela incisão na pele de aproximadamente $30 \mathrm{~cm}$, seguindo pelo afastamento em seu sentido longitudinal das fibras musculares dos músculos que compõem a parede abdominal. Após incisão do peritôneo, procedeu-se a exposição de um segmento dorsal do rúmen e sua fixação à pele por meio de sutura de reparo em padrão simples separado, com fios de algodão 3-0, alcançando apenas as camadas serosa e muscular. Com o rúmen fixado e a ferida da parede abdominal protegida com compressas esterilizadas, praticou-se uma incisão de $15 \mathrm{~cm}$ na sua superfície até atingir a luz do órgão. Após o esvaziamento parcial do rúmen e aplicação do primeiro plano de sutura em sua parede empregando-se fios de algodão 3-0 em padrão Schmieden, o instrumental cirúrgico foi substituído por outro esterilizado. A partir desse momento, quando os bovinos operados pertenciam aos grupos GI e GII o cirurgião e auxiliar trocavam a vestimenta por outra também esterilizada para em seguida realizar o segundo plano de sutura no órgão. Quando a operação era realizada nos animais pertencentes aos grupos III e IV, após substituir o instrumental cirúrgico, o cirurgião e seu auxiliar não substituíam a vestimenta por outra esterilizada, limitando-se a repetir a higienização das mãos e antebraços, com água e sabão, hipoclorito de sódio e solução de iodo, seguindo o mesmo procedimento adotado no pré-operatório. Finalmente, o segundo plano de sutura do rúmen era concluído. Em todos os animais dos diferentes grupos, procurou-se evitar o contato do conteúdo rumenal com os tecidos, utilizando-se além das compressas, panos de campo previamente fixados nas bordas da ferida cutânea e na superfície exposta do rúmen. No pós-operatório, os animais que compuseram os grupos I e III receberam oxitetraciclina de longa ação ${ }^{\mathrm{d}}$, pela via intramuscular, na dose de $20 \mathrm{mg} \mathrm{kg}^{-1}$ de peso corporal a cada 48 horas, perfazendo um total de quatro aplicações, sendo a primeira dose aplicada imediatamente após a conclusão do procedimento cirúrgico. Sobre a ferida cirúrgica, aplicou-se, diariamente, até a cicatrização clínica, uma fina camada de um produto larvicida à base de dicloro-divinil- pirrolidona (DDVP) 1,6g, butano e permetrinae. Nos animais pertencentes aos grupos II e IV, não se utilizou antibiótico parenteral nem tratamento da ferida cirúrgica, exceto quando era detectada a presença de miíase. Nestes casos, aplicava-se o mesmo produto utilizado nas feridas cirúrgicas dos animais dos grupos I e III. A remoção dos pontos ocorreu entre o $10^{\circ}$ e $14^{\circ}$ dias do pós-operatório, e durante 30 dias os animais foram avaliados clinicamente, com o objetivo de observar possíveis complicações pós-cirúrgicas como: deiscência de ferida, edema, enfisema e abscesso subcutâneos, peritonite, fístula rumenal e óbito. Ao final do estudo, para avaliar a evolução da ferida cirúrgica dos bovinos de todos os grupos, adotaram-se os seguintes escores clínicos de cicatrização: Grau 0 ausência de cicatrização; Grau 1 - cicatrização de aproximadamente $25 \%$ da ferida; Grau 2 - cicatrização de 50\%; Grau 3 - cicatrização de $75 \%$ e Grau 4 cicatrização de $100 \%$ da ferida. Feridas com escores superiores ou iguais a $75 \%$ foram consideradas cicatrizadas.

Os resultados obtidos foram analisados por meio do Teste Exato de Fisher (MONTEIRO FILHO, 2003) que comparou os efeitos da paramentação e da antibioticoterapia sobre a ocorrência de complicações pós-operatórias. Em relação a cada grupo estudado, foi calculado o intervalo de confiança de $95 \%$ para o número de complicações pós-operatórias.

\section{RESULTADOS E DISCUSSÃO}

Na técnica cirúrgica realizada com o animal contido em decúbito lateral, mesmo adotando todas as precauções, torna-se inevitável o contato de uma parcela do material extraído do rúmen com diferentes planos anatômicos da parede abdominal. Por esse motivo, é possível inferir que as complicações pósoperatórias observadas no tecido subcutâneo tenham sido originadas, em parte, pelo seu contato com o conteúdo rumenal. Neste estudo, apesar de terem sido adotadas todas as condutas técnicas adequadas ao procedimento, os resultados obtidos relacionados às complicações pós-operatórias, contradizem as citações de HERING et al. (1993), os quais afirmaram que a técnica operatória perfeita evita o aparecimento do meio de cultura para os microrganismos pela ausência de hematomas e de necrose na ferida operatória, mas existe uma tendência em se superestimar os fatores bacterianos em detrimento do fator técnico.

A opção pela cirurgia com os bovinos em decúbito lateral, deveu-se ao fato de ter-se utilizado neste experimento animais mestiços, sabidamente de temperamento mais sangüíneo, mesmo considerando 
os potenciais riscos de uma eventual contaminação ambiental da ferida cirúrgica. TAVARES (1993) mencionou que a contaminação do campo operatório por uma pequena quantidade de germes provenientes do ambiente é praticamente inevitável. Entretanto, essa contaminação exógena é de pequena importância, visto que as defesas naturais do organismo impedem o desenvolvimento bacteriano.

Dentre as complicações pós-operatórias diagnosticadas nos animais do grupo I (Tabela 1) observou-se: edema subcutâneo em sete animais (100,0\%) e enfisema subcutâneo em três (42,9\%). Nos bovinos do grupo II, ocorreram cinco casos $(71,4 \%)$ de edema subcutâneo, dois (28,6\%) de enfisema subcutâneo e um $(14,3 \%)$ de deiscência de ferida, corroborando os achados de SANNI et al. (2002) os quais enfatizaram que a rumenotomia pode resultar em complicações pós-operatórias como edema, infecção, peritonite, morte, obstrução e/ou aderência intestinal e miíases. Ratificando em parte os achados encontrados no presente estudo, WILLIAM et al. (1990) afirmaram que, nesse tipo de procedimento cirúrgico, complicações pós-operatórias como timpanismo, deiscência de ferida e toxemia são freqüentemente observados.

De acordo com os intervalos de confiança de 14,4 \pm 1,3 e 15,1 \pm 3,2, em dias, para os grupos I e II respectivamente, e ao nível de significância (NS) de $5 \%$, não se observou diferença significativa entre o número de complicações pós-operatórias diagnosticadas nos bovinos pertencentes aos dois grupos, sugerindo que, na execução da rumenotomia em bovinos com os animais contidos em decúbito lateral, mesmo adotando o uso de avental cirúrgico e de luvas esterilizadas, não foi possível evitar a ocorrência de várias complicações pós-operatórias, inclusive a deiscência de ferida. Acrescenta-se que essa complicação e ocorrência de abscessos podem também estar relacionadas com o fio utilizado na sutura, uma vez que fios multifilamentares não absorvíveis podem abrigar bactérias no interior dos interstícios das suturas, criando barreira a uma eficiente fagocitose, conseqüentemente, comprometendo a reparação tecidual, conforme afirmou SMEAK (1996). Observações semelhantes foram encontradas por FAGUNDES \& KHARMANDAYAN (1991) e HERING et al. (1993) de que o fio de algodão ou de seda, por serem multifilamentados, apresentam capilaridade e, conseqüentemente, maior absorção de líquidos nas feridas, além de facilitar a aderência bacteriana. Ressalta-se que, apesar de reconhecer desvantagens apresentadas pelo uso do fio de algodão, neste estudo a escolha deveu-se em razão de questões econômicas, praticidade, disponibilidade no mercado e segurança na sutura de pele.

Os dez casos $(35,7 \%)$ de enfisema subcutâneo, observados no pós-operatório dos bovinos deste estudo podem ser atribuídos à contaminação por determinados microrganismos produtores de gases. Ao contrário, Jones \& Cosma (1985), apud WILLIAM et al. (1990), atribuíram a presença de enfisema subcutâneo após rumenotomia, à liberação de ar da cavidade abdominal ou por espasmo capilar no tecido subcutâneo devido à ação bifásica do anestésico local.

Abscessos subcutâneos diagnosticados nos animais dos grupos III e IV, podem ser decorrentes da possível presença na ferida cirúrgica, de microorganismos oriundos do conteúdo rumenal e não devido à necrose de pele nas camadas superficiais causada pela alta concentração de adrenalina presente no anestésico local, resultando em espasmo capilar apontado por (OEHME \& PRIER,1980).

Ocorreu um óbito (14,3\%) entre os animais do grupo III no oitavo dia do pós-operatório, e a causa da morte foi atribuída à peritonite diagnosticada por ocasião da necropsia. Essa complicação, segundo HEIDRICH et al. (1980), é observada com freqüência no bovino, e geralmente ocorre após perfuração do estômago ou intestino. Na peritonite generalizada, o tratamento não é compensador, e na focal recomendase antibioticoterapia parenteral ou pela via intraperitoneal por três a quatro dias. Nos demais, dois bovinos (28,6\%) apresentaram enfisema subcutâneo, que a partir do quinto dia desapareceu gradativamente. Foram observados três casos (42,9\%) de deiscência de ferida cirúrgica e três animais (42,9\%) apresentaram abscessos subcutâneos que foram drenados e higienizados com hipoclorito de sódio a $0,5 \%$. Todos os animais desse grupo apresentaram edema subcutâneo. Necrose de pele na região do flanco esquerdo foi observada em um animal (14,3\%), provavelmente em decorrência do uso de anestésico local contendo vasoconstritor.

Dentre os bovinos que compuseram o grupo IV, três $(42,9 \%)$ apresentaram enfisema subcutâneo, em quatro animais $(57,1 \%)$ foi diagnosticado abscesso subcutâneo, e em um animal (3,6\%) observou-se a formação de fístula rumenal, possivelmente em função de uma peritonite focal (Tabela 1). Todos os animais do grupo IV apresentaram edema e deiscência parcial de ferida, mas a recuperação clínica ocorreu em média aos 25 dias, ocasião em que os curativos foram interrompidos. WILLIAM et al. (1990), avaliando o pós-operatório de 23 bovinos submetidos à rumenotomia para o tratamento de 
Tabela 1 - Número de complicações observadas em fêmeas bovinas na faixa etária de 20 meses submetidas a rumenotomia utilizando-se a paramentação convencional do cirurgião, ou a higienização das mãos e antebraços e, no pós-operatório antibioticoterapia parenteral com oxitetraciclina de longa ação, na Escola de Veterinária da Universidade Federal de Goiás, no período compreendido entre 1994 e 2002.

\begin{tabular}{|c|c|c|c|c|c|}
\hline \multirow{2}{*}{ Complicações pós-operatórias } & \multicolumn{4}{|c|}{ Grupos } & \multirow{2}{*}{ Total \%* } \\
\hline & GI & GII & GIII & GIV & \\
\hline Edema & 7 & 5 & 7 & 7 & 92,9 \\
\hline Necrose de pele & - & - & 1 & - & 3,6 \\
\hline Deiscência de ferida & - & 1 & 3 & 7 & 39,3 \\
\hline Enfisema subcutâneo & 3 & 2 & 2 & 3 & 35,7 \\
\hline Abscesso subcutâneo & - & - & 3 & 4 & 25,0 \\
\hline Peritonite & - & - & 1 & 1 & 7,1 \\
\hline Fístula rumenal & - & - & - & 1 & 3,6 \\
\hline Óbito & - & - & 1 & - & 3,6 \\
\hline
\end{tabular}

* Ocorrência de complicações pós-operatórias em relação ao total de animais estudados.GI: Paramentação do cirurgião e auxiliar e antibioticoterapia com oxitetraciclina no pós-operatório; GII: Paramentação do cirurgião e auxiliar; GIII: Não se utilizou a paramentação do cirurgião e do auxiliar, mas usou antibioticoterapia com oxitetraciclina no pós-operatório; GIV: Não se realizou a paramentação e nem antibioticoterapia no pós-operatório.

enfermidades no trato gastrintestinal, diagnosticaram enfisema subcutâneo, peritonite, timpanismo, deiscência de ferida, abscesso e óbito.

A recuperação dos animais pertencentes aos grupos III e IV também foi analisada através do intervalo de confiança estabelecido, não se observando diferença significativa entre eles. Diante dos resultados encontrados, pode-se deduzir que, quando não se adotou a paramentação do cirurgião e do auxiliar, o uso de antibiótico parenteral não influenciou no tempo de recuperação dos animais. FULLER (2000) relatou que todos os tipos de vestimenta cirúrgica têm por objetivo servir de barreira entre os focos de contaminação e o paciente ou a equipe, não permitindo que os padrões de assepsia dêem lugar ao conforto do cirurgião em detrimento do bem-estar animal. Segundo TURNER \& McILWRAITH (2002), a classificação da cirurgia é importante na decisão de usar ou não a antibioticoterapia ou antecipar a probabilidade de infecção pós-operatória. Como exemplo, encontram-se as cirurgias denominadas contaminadas limpas, tais como aquelas realizadas no trato gastrintestinal sem ocorrer derrame significativo de conteúdo contaminado.

Ao comparar a conduta estabelecida entre os grupos I e III com II e IV, em relação à paramentação, verificou-se diferença significativa, podendo-se argumentar que a paramentação foi um fator que contribuiu positivamente na redução do tempo de cicatrização, tanto entre os animais nos quais se utilizou o antibiótico, como naqueles em que essa medida não foi adotada. SAINI et al. (1992), ao realizarem laparotomia em bovinos e avaliarem o uso local e parenteral de estreptopenicilina, observaram que, independente da via de aplicação do medicamento, a ferida cirúrgica dos animais que receberam esta antibioticoterapia apresentou excelente recuperação. HAVEN et al. (1992) concluíram que não existe diferença significativa quanto ao emprego de uma única dose de penicilina $\mathrm{G}$ potássica no pré-operatório e o uso de penicilina $G$ procaína por um período de sete dias após a intervenção cirúrgica de rumenotomia praticadas em bovinos. Contrariando tais achados, CANABRAVA et al. (2000) afirmaram que a administração parenteral de antibiótico 60 minutos antecedendo o procedimento cirúrgico em bovinos não apresentou benefícios, e KERSJES et al. (1986) indicaram o uso de antibiótico após a rumenotomia, além de medidas dietéticas. TAVARES (1993) citou estudos nos quais demonstraram que o momento definitivo em que se dá a infecção cirúrgica situa-se durante o ato cirúrgico. Portanto, para que possa exercer sua ação profilática, o fármaco deve estar circulando e presente nos tecidos do paciente no momento em que se dá a invasão bacteriana, e por esse motivo deve ser prescrita pouco antes de se iniciar a cirurgia ou durante o início do ato cirúrgico.

Analisando o tempo de recuperação dos animais, verificou-se que, entre os grupos, houve diferença significativa $(\mathrm{P}<0,001)$ (Tabela 2$)$. Independente do grupo, a cicatrização clínica completou-se, em média, aos 15 dias, exceto em sete animais $(25,0 \%)$ em que ocorreram abscessos e onze (39,3\%) que apresentaram deiscência de ferida. Nesses 
Tabela 2 - Comparação entre os grupos, de acordo com o tempo médio de cicatrização (em dias) das feridas cirúrgicas em fêmeas bovinas submetidas à rumenotomia, na Escola de Veterinária da Universidade Federal de Goiás, no período compreendido entre 1994 e 2002.

\begin{tabular}{|c|c|c|c|c|c|}
\hline \multirow{2}{*}{ Grupo } & \multirow{2}{*}{ Número de complicações } & \multirow{2}{*}{ Média** } & \multirow{2}{*}{ Desvio padrão } & \multicolumn{2}{|c|}{ IC da média } \\
\hline & & & & Mínimo & Máximo \\
\hline G I & 7 & $14,4^{\mathrm{a}}$ & 1,3 & 13,3 & 15,6 \\
\hline G II & 7 & $15,1^{\mathrm{a}}$ & 3,2 & 12,2 & 18,1 \\
\hline G III & $6 *$ & $22,7^{\mathrm{b}}$ & 3,6 & 18,9 & 26,4 \\
\hline G IV & 7 & $26,4^{\mathrm{b}}$ & 2,1 & 24,5 & 28,3 \\
\hline
\end{tabular}

*Um óbito; $\mathrm{F}=33,635 ; \mathrm{p}<0,001$;.

** Letras diferentes indicam diferença entre médias.

casos, os animais foram considerados recuperados em média aos 25 dias do pós-operatório. Nos animais em que ocorreram abscessos e deiscência de ferida, drenou-se o conteúdo e higienizou-se com hipoclorito de sódio até completa cicatrização clínica. Para CASTRO et al. (2003), a utilização de hipoclorito de sódio no tratamento de abscessos drenados cirurgicamente influenciou na redução de recidivas, além de apresentar maior poder de cura em comparação ao uso de uma simples lavagem com água e sabão.

Levando-se em consideração os escores de cicatrização clínica estabelecidos para avaliar a evolução da ferida cirúrgica, ao final do estudo considerou-se que 27 animais (96,43\%) apresentaram escore de cicatrização 3 e 4, atingindo portanto, níveis desejados de recuperação. Um animal (3,6\%) pertencente ao grupo GIV apresentou escore 2 de cicatrização, em razão da ocorrência de fístula rumenal.

A análise comparativa quanto à influência ou não da paramentação e do uso de antibiótico sobre cada uma das complicações pós-operatórias, separadamente, indicou que a paramentação pode ter evitado o surgimento de deiscência de ferida $(\mathrm{P}=$ 0,001) e de abscessos subcutâneos ( $\mathrm{P}=0,003)$. Quanto às demais complicações, a paramentação não exerceu influência. Já o uso da oxitetraciclina pode ter influenciado na recuperação dos animais que apresentaram deiscência de ferida $(\mathrm{P}=0,051)$ (Tabela 2). Quanto a esse aspecto, resultados semelhantes foram encontrados por HAVEN et al. (1992) demostrando que bovinos submetidos à rumenotomia e recebendo antibioticoterapia (penicilina $G$ potássica e $G$ procaína) acusaram uma recuperação melhor, quando comparados com aqueles que não a receberam. Segundo TURNER \& McILWRAITH (2002), prevenir uma infecção pósoperatória deve ser a meta de todo cirurgião. Entretanto, quando as medidas profiláticas adotadas não são suficientes para se evitar tal complicação ou se o animal não conseguir debelar o processo infeccioso utilizando seus próprios mecanismos de defesa, pode ser necessário realizar a drenagem dos ferimentos ou instituir um tratamento com antibióticos.

\section{CONCLUSÕES}

A paramentação contribui positivamente, para a redução do tempo de cicatrização das feridas cirúrgicas, tanto em animais nos quais se utiliza a oxitetraciclina parenteral quanto naqueles em que a medicação não é empregada. Quando não se adota a paramentação do cirurgião e do auxiliar, o uso de antibiótico parenteral não influencia na cicatrização das feridas cirúrgicas.

\section{FONTESDEAQUISIÇÃO}

\author{
a Dorcipec ${ }^{\circledR}$. Vallée S.A. São Paulo SP \\ ${ }^{\mathrm{b}}$ Iodophor $^{\circledR}$. Fatec. São Paulo SP. \\ ${ }^{\mathrm{c}}$ Anestésico Pearson ${ }^{\circledR}$. Pearson Saúde Animal Ltda. São Paulo \\ SP. \\ ${ }^{\mathrm{d}}$ Oxitrat L.A ${ }^{\circledR}$. Vallée S.A. São Paulo SP. \\ e Mata Bicheira Purina ${ }^{\circledR}$. Purina Agribrands do Brasil São Paulo \\ SP.
}

\section{REFERÊNCIAS BIBLIOGRÁFICAS}

BLESSING, C.E. Prevention of postoperative eventrations in large animal abdominal surgery. Veterinary College Cornell University, New York, v.14, p.239-241, 1971.

CANABRAVA, H.A.N. et al. Antibiótico profilaxia na cirurgia de fixação do pênis à parede abdominal em bovinos. In: CONGRESSO BRASILEIRO DE CIRURGIA E ANESTESIOLOGIA VETERINÁRIA, 4., 2000, Goiânia, GO. Anais... Goiânia : Universidade Federal de Goiás, 2000. V.1, 296p, p.127.

CASTRO, G.R. et al. Utilização do hipoclorito de sódio no tratamento de abscessos subcutâneos pós-vacinais em bovinos. In: ENCONTRO DE INICIAÇÃO CIENTIFICA E III EPG ENCONTRO DE PÓS-GRADUAÇÃO, 7., 2003, São Carlos, Brasil. Anais... São Carlos : Universidade do Vale do Paraíba UNIVAP, 2003. Cd Rom.

Ciência Rural, v.35, n.3, mai-jun, 2005. 
DEHGHANI, S.N.; GHADRDANI, A.M. Bovine rumenotomy: comparison of four surgical techniques. Canadian Veterinary Journal - Revue Veterinaire Canadienne, v.36, n.11, p.693-697, 1995.

EL-MAGHRABY, H.M.; HAILAT, N. Surgical correction of displaced associated with ruminal and/or reticular foreign bodies in cattle. Praktische - Tierarzt, Irbid, v.82, n.3, p.201205, 2001.

FAGUNDES, D.J.; KHARMANDAYAN, P. O fio cirúrgico. Acta Cirúrgica Brasileira, São Paulo, v.6, n.4, p.177-181, 1991.

FULLER, J.R. Tecnologia cirúrgica: princípio e prática. 3.ed. Rio de Janeiro : Guanabara Koogan, 2000. 623p.

GONZALO, J.M. et al. Cirurgia veterinária. Madrid: Interamericana, 1994. 884p.

HAVEN, M.L. et al. Effects of antibiotic profilaxis on postoperative complications after rumenotomy in cattle. Journal American Veterinary Medical Association, Raleigh, v.200, n.9, p.132-135, 1992.

HEIDRICH, H.D. et al. Manual de patologia bovina. São Paulo : Varela, 1980. 310p.

HERING, F.L.O. et al. Bases técnicas e teóricas de fios e suturas. São Paulo : Roca, 1993. 172p.

KERSJES, A.W. et al. Atlas de cirurgia dos grandes animais. São Paulo : Manole, 1986. 143p.

KNECHT, C.D. et al. Técnicas fundamentais em cirurgia veterinária. São Paulo : Roca, 1985. 308p.

LAZZERI, L. Técnica operatória veterinária. Belo Horizonte : Escola de Veterinária, UFMG, 1994. 415p.
MASSONE, F. Atlas de anestesiologia veterinária. São Paulo : Roca, 2003. 172p.

MONTEIRO FILHO, G. Estatística prática geral. Goiânia: Vieira, 2003. 230p.

OEHME, P.W.; PRIER, J.E. Textbook of large animal surgery. 2.ed. Baltimore : Wiikins, 1980. 412p.

ROSENBERGER, G. Exame clínico dos bovinos. Rio de Janeiro : Guanabara Koogan, 1993. p.420.

SAINI, N. S. et al. Evaluation of local and parenteral use of antibiotics during laparotomy in bovines. Indian Veterinary Journal, v.69, p.150-154, 1992.

SANNI, B.D. et al. Post surgical complications from student's large animal surgical exercise. Nigerian Veterinary Journal, Zaria, v.23, n.2, p.40-45, 2002.

SILVA, L.A.F. et al. Estudo etiológico de abscessos mamários em vacas leiteiras e utilização do hipoclorito de sódio a $1 \%$ no tratamento pós-operatório. Napgama, São Paulo. v.5, n.2, p.7-11, 2002.

SMEAK, D.D. Escolha e uso dos materiais de sutura atualmente disponíveis. In: BOJRAB, M.J. Técnicas atuais em cirurgia de pequenos animais. 3.ed. São Paulo : Roca, 1996. Cap.3, p.33-38.

TAVARES, W. Manual de antibióticos e quimioterápicos antiinfecciosos. Rio de Janeiro : Atheneu, 1993. 770p.

TURNER, A.S.; McILWRAITH, C.W. Técnicas cirúrgicas em animais de grande porte. São Paulo : Roca, 2002. 341p.

WILLIAM, B.J. et al. Post-operative complications of rumenotomy. Indian Veterinary Journal, Tamil Nadu, v.67, n.12, p.1161-1162, 1990. 